\title{
Exposure Factors Associated with Visceral Leishmaniasis (kala-azar) in Loima Sub-County of Turkana County, Kenya
}

\author{
Joseph Akutaa Lotukoi ${ }^{1, *}$, Hellen Lydia Kutima ${ }^{2}$, Christopher Anjili ${ }^{3}$, Peter Wanzala ${ }^{4}$ \\ ${ }^{1}$ Department of Public Health, Jomo Kenyatta University, Institute of Tropical Medicine and Infectious Diseases, Nairobi, Kenya \\ ${ }^{2}$ Department of Zoology, Jomo Kenyatta University, Nairobi, Kenya \\ ${ }^{3}$ Centre for Biotechnology Research and Development, Kenya Medical Research Institute (KEMRI). Nairobi, Kenya \\ ${ }^{4}$ Centre for Public Health Research (CPHR), Kenya Medical Research Institute (KEMRI), Nairobi, Kenya
}

\section{Email address:}

jlotukoi@yahoo.com (J. A. Lotukoi),hkutima@gmail.com (H. L. Kutima), canjili@kemri.ac.ke (C. Anjili), Pwanzala2003@gmail.com (P. Wanzala)

*Corresponding author

\section{To cite this article:}

Joseph Akutaa Lotukoi, Hellen Lydia Kutima, Christopher Anjili, Peter Wanzala. Exposure Factors Associated with Visceral Leishmaniasis (kala-azar) in Loima Sub-County of Turkana County, Kenya. American Journal of Laboratory Medicine. Vol. 2, No. 6, 2017, pp. 144-155. doi: $10.11648 /$ j.ajlm.20170206.16

Received: November 30, 2016; Accepted: December 24, 2016; Published: November 8, 2017

\begin{abstract}
Background: Visceral Leishmaniasis (Kala-azar) is a serious disease caused by species of the parasitic protists Leishmania. It can affect humans living in parts of the tropics and sub-tropics and is transmitted by Phlebotomus sandflies. It is classified as a neglected disease yet it is a public health problem, a debilitating disease causing an estimated 500,000 new cases each year, and a tenth of these patients will die in the predisposed areas. Objective: To assess the exposure factors associated with kala-azar in Loima sub-county of Turkana County, Kenya. Methods: Descriptive cross- sectional research design was employed and the study was conducted between October, 2015 and June, 2016. Cluster random sampling technique was used to identify study subjects in the purposively selected Loima Sub-county. A sample size of 341 respondents who were household heads or adult members and health facility workers were randomly sampled. Data collection was done using pretested structured questionaires, interviews, focus group discussions and observations; entered into Statistical Package for Social Sciences (SPSS) version 17.0 for analysis. Presentation of data was done using both quantitative and qualitative approaches. Results: The key exposure factors to the disease in the community include: Age, gender, educational level, socio-economic status, housing, presence of large amount of termite mounds all over the area $60.1 \%(n=205)$,inaccessibility to health services, varying health-seeking behaviour and lack of proper knowledge on transmission of disease. Also, human activities such as deforestation and hunting $52 \%(\mathrm{n}=32)$, resting or sitting near termite mounds $70 \%(\mathrm{n}=191)$ and dancing at night (Edong'a $64.8 \%(n=167)$, when the sand flies are active. There was a significant association between age $((\mathrm{OR}=0.7 ; 95 \% \mathrm{CI}=(0.4-1.1)$, $\mathrm{p}=0.135)$ and exposure to kala-azar, gender $(\mathrm{OR}=0.6 ; 95 \% \mathrm{CI}=(0.4-0.9), \mathrm{p}=0.012)$, education level $(\mathrm{OR}=1.2 ; 95 \% \mathrm{CI}=(0.1-1.4)$, $\mathrm{p}=0.0501))$, housing $(\mathrm{OR}=1.8 ; 95 \% \mathrm{CI}=(1.0-3.1), \mathrm{p}=0.029)$, presence of large amount of termite mounds $(\mathrm{OR}=0.6 ; 95 \% \mathrm{CI}=$ $(0.2-2.0), p=0.0045)$ and resting or sitting near termite-mounds $(\mathrm{OR}=0.6 ; 95 \% \mathrm{CI}=(0.1-2.1), \mathrm{p}=0.0043))$. Conclusion: The study concludes that kala-azar is prevalent in the area and though the community is aware of its existence, the residents have different beliefs about transmission. The study recommends the need for enhanced general health education and awareness on the transmission cycle of kala-azar. Community empowerment and participation should be emphasized as well as structural development plans that include sand fly management strategies and control methods that would ensure the removal of breeding and resting sites of the vectors within human habitation. In addition, integrated disease surveillance and response to be implemented to avert the disease situation.
\end{abstract}

Keywords: Visceral Leishmaniasis, Kala-Azar, Exposure, Loima, Kenya 


\section{Introduction}

\subsection{Background Information}

Visceral leishmaniasis has been among the most important health problems since early 1900s, in the world and SubSaharan Africa especially Kenya and Sudan where major upsurges in the number of cases were and still are noted in the endemic areas. Though a forgotten tropical parasitic disease, it causes an estimated 500000 new cases yearly and a tenth of these patients will die; and that it is almost always fatal with a mortality rate of almost $100 \%$, if the cause is not identified and if left untreated [1]. The actual toll death of the disease may be higher than this estimate, considering the existence of its unidentified foci. Current estimates suggest an overall prevalence of 12 million people infected with Kala-azar in an at -risk population of 350 million, suggesting more than 2 million new infections each year with the figures including only cases with the overt disease [2]. In terms of Disability -Adjusted Life Years, the disease is responsible for a loss of 34 DALYS [3]. The geographical distribution of the disease in the predisposed areas is limited by the distribution of the sand fly, its susceptibility to cold climates, its tendency to take blood from humans or animals only and its capacity to support the internal development of specific species of Leishmania [4].

In Kenya, the disease has been reported in Baringo, Kitui, Machakos, West Pokot and Turkana where the prevalence is high especially in Loima Sub-county. More recently Kalaazar has been reported in Kerio Valley, North Baringo East Pokot, Wajir and Mandera Districts in North Eastern Province [5]. In Pokot and Turkana areas, Kala-azar has existed for at least 40 years. WHO 1991 report on the epidemiology of kala-azar, mentioned a survey done in 1959 where a high prevalence of the disease was confirmed in the area(s). Two annual reports of Amudat Hospital, Uganda (1983, 1985) that borders West Pokot and Turkana, mentioned kala-azar as frequently being predisposed to the people in Kenya and Uganda. Loima one of the six Subcounties of Turkana County, has a high kala-azar prevalence against a population of 50000 people [6].

The geographical distribution of kala-azar in Africa including Kenya is due to factors related to development including poverty due to low socio-economic status and socio cultural practices, inaccessibility to health services, vector dynamics, massive rural- urban migration and agro-industrial projects that bring non-immune urban dwellers into endemic rural areas. Man- made projects with environmental impact like dams, irrigation systems and wells as well as deforestation, also contribute to the spread of leishmaniasis [7].

\subsection{Statement of the Problem}

The increasing number of people infected with kala-azar in Kenya and other countries poses a major public health problem, mostly in arid and semi- arid areas like Loima District of Turkana county, where many people are exposed and is endemic with a higher prevalence against a population of 50,000 people. This trend risks causing a health crisis as the disease is becoming a lethal cocktail, hence efforts need to be taken to avert the situation. The disease is fatal such that if not detected early, can result into deaths within a short period and that its mortality rate is almost $100 \%$ and it can result into epidemic outbreaks. The case fatality rate associated with the disease range from $0-50 \%$ of treated cases to $85-99 \%$ of untreated cases. The disease is a silent killer, invariably killing almost all untreated patients [8].

Kala-azar often exists in areas that are either remote or not easily accessible areas where health facilities are barely available or inadequate. Those most likely to be infected are people who are poor, living in villages far from roads and health care centres. Patients from such remote communities often die in the villages without seeking treatment. Some may attempt to report to distant health care centres, but in many cases it is simply too late. Even if they can make the journey to a hospital, they would still succumb to the illness because of the absence of anti- leishmanial drugs. Thus many decide to stay at home until they die. But in doing so, they act as a reservoir of infection, passing on the parasite to the family and neighbors through the bite of sand flies, hence the prevalence and incidence increase [1,9].

Kala -azar affects not only the Weakest in the community such as children and those weakened by other diseases such as HIV and tuberculosis, but also healthy adults and economically productive social groups [10] Most Kala-azar infections occur in remote geographical areas where say health facilities are not well established and where the infections often co-exist with malaria and other debilitating parasitic infections. Under this circumstance the disease usually presents a diagnostic dilemma, hence the need to determine the real cause of exposure in an area. Untreated Kala-azar is usually fatal in that even after recovery; patients may develop the chronic form that requires prolonged and expensive therapy [11].

\section{Materials and Methods}

\subsection{Study Area and Study Population}

The study was conducted in Loima Sub-county of Turkana county, Kenya from October 2015 to June, 2016. Loima (shown in figure 1 below) is part of Turkana County of the Rift Valley Province of Kenya, and which is suspected to have more people being predisposed to Kala-azar [8]. Turkana county occupies the northwestern part of Kenya sharing international borders with Ethiopia to the North, Sudan to the northwest and Uganda to the West, which are areas where also kala-azar is endemic. Turkana county is an arid and semi-arid land with warm and hot climates, unreliable rainfall where it receives annual rainfall of between $120 \mathrm{~mm}$ and $500 \mathrm{~mm}$ in the lowlands and highlands respectively and, with temperatures ranging between 24380C. The main economic activities include livestock farming and trade, fishing, weaving and tourism. Natural 
resources are gemstone and saltlicks, oil,gold that is dormant, wildlife,Lake Turkana and Turkwell dam. Agricultural products are sorghum and maize. Despite all these, the poverty level is that $95 \%$ of the population live below the poverty line, 89.4 being the age dependence ratio.

Loima Sub-county covers an area of approximately $4,250 \mathrm{~km}^{2}$ comprising of two geographically distinct regions, Lorengippi region $\left(2,050 \mathrm{Km}^{2}\right)$ and Loima hills plateau $\left(2,200 \mathrm{Km}^{2}\right)$. Landforms in the district include mountains, hills, uplands, foot slopes, dissected erosional plains, sedimentary plains and riverine (flood) plains. The vegetation comprises of evergreen woodlands, deciduous bush land, deciduous bush annual 34 grassland, and wooded grassland and it is within $10 \mathrm{Km}$ of permanent water. It receives a median annual rainfall of $200-400 \mathrm{~mm}$. Loima Sub-county has three divisions with an estimated human population of 50,000 people in 6,000 households [12]. It is in the Western part of the county, sharing borders with West Pokot District to the South and Uganda to the West. Majority (55\%) of the houses in the study area had mud-plastered walls with a tiled or thatched roof. The remainder were brick, made with either cement plaster or without cement plaster. Majority of the houses had a mud floor. The floors and walls are usually smeared with mud and cow excrements. The majority of the population were indigenous inhabitants with some inmigrants from near-by districts, such as Turkana South, West and Turkana Central. The population was of different socioeconomic strata, with the unemployed being 50.5\% $(n=172)$ as compared to employed $49.5 \%(n=169)$ that comprised mainly of cattle keepers, casual, skilled, and laborers engaged in business and some subsistence farming. The overall literacy level was low; males had higher levels than females.

The health in the sub- county is such that there are seventeen (17) health facilities, four (4) with diagnostic services and only one health facility-Pentecostal Assemblies of God (PAG) faith based health centre is equipped for kalaazar diagnosis. The infant and under five mortality rates are $60 / 1000$ and 12/1000 respectively. The prevalent diseases include malaria, malnutrition, pneumonia or respiratory infections, diarrhea and neglected diseases like Kala-azar.

\section{TURKANA COUNTY LIVELIHOOD ZONES}

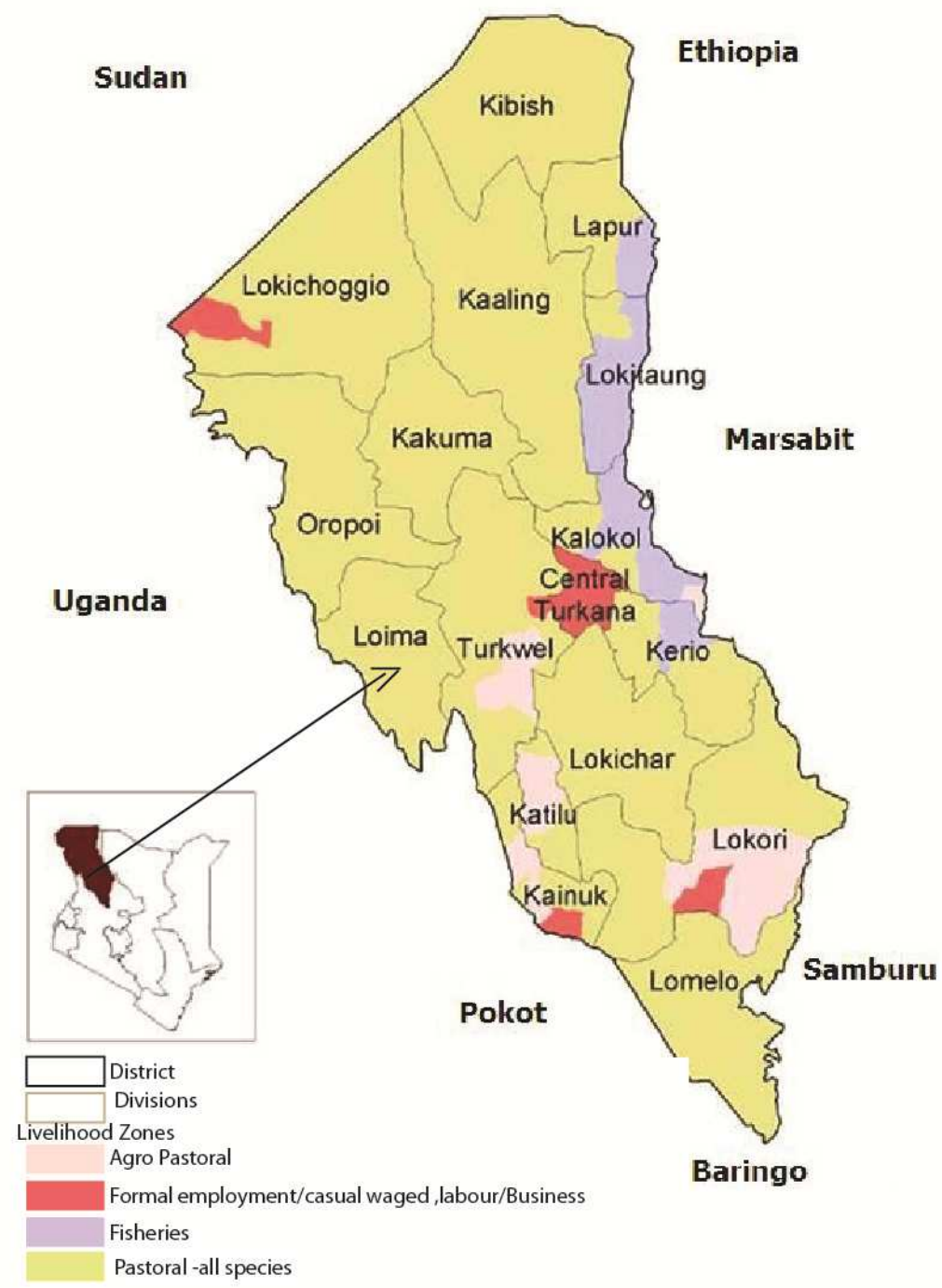

Figure 1. Map of Kenya showing the Turkana county and the study area [12]. 


\subsection{Study Design}

A descriptive cross-sectional design that entails adoption of both the quantitative and qualitative data collection methods (mixed methods), was employed to determine the epidemiological, the social demographic characteristics, economic or socio-medical factors, health seeking behavior, disease transmission dynamics, local people's attitude, perception, knowledge and behavior towards the existence of kala-azar in the area, as the selected variables to be measured, among other factors [13]. The people at risk of disease were considered in relation to their sociodemographic characteristics, housing conditions, income level, socio-cultural practices or behaviour predisposing them to the disease as well as being a resident in the kala-azar endemic area for more than six (6) months.

\subsection{Sampling Procedures}

The county was purposely selected because it contained the population of interest. The Su-county was also purposively selected because according to MSF survey of 2004, the area has the highest prevalence of Kala-azar in comparison with other sub-counties, meaning that more people in the District are predisposed to the disease. Cluster random sampling was used to randomly select the divisions, locations, villages and the households that were sampled in order to obtain the required sample size. The standard formula as used by Bartlett et al; (2002 [14] and Lwanga and Lemeshow (1991), lead to arriving at 341 respondents and the sampling method was determined using probability sampling [13] and the study area clusters. The population in the clusters or locations and villages vary and to maintain an equal representation, a proportion commensurate to the number of household in the clusters was calculated (13]. The target population was stratified into units of households and only one member of the household (head or adult member) was interviewed. A list of the households was obtained from the area chief and the community health worker in charge of the location and the simple random sampling was used in enrolling an household for an interview.

\subsection{Data Collection}

Pretested structured questionnaires adopted from different literatures were employed to collect the quantitative data in this study from the randomly selected household heads or adult members. The questionnaires were constructed according to each objective and hypothesis of the study. Focus group discussions, key informat interviews and observations were used to collect qualitative data. Key informant interviews was conducted with elders, provincial administrators, other opinion leaders and the selected health facilities workers such as the doctors, nurses clinical officers, medical laboratory technologists and public health officers, all who are directly involved in the diagnosis, management, prevention and control of kala-azar. The selected community workers, opinion leaders and other stakeholders were also involved in the focus group discussions. Qualitative data collected was conceptualized, coded, categorized and summarized based on the themes and according to each objective of the study. The data collection instruments were first prepared in English and then translated in to Turkana language and back translated to English by principal investigator and language experts to check for its consistency.

\subsection{Quality Assurance}

A pilot study was done in the Turkwell locations and sublocations not chosen but had similar characteristics with the chosen ones, in order to ascertain the validity, reliability and suitability of the data collection instruments. Research assistants (4), were trained for one day on the use of interview schedules, making respondents understand questions, objectives and the significance of the study as well as explaining to them that participation is voluntary. They also helped in the interpretation of the local Turkana language for those who may not have understood Kiswahili/English, filling answers in the interview schedules and also assisted in locating the randomly selected respondents. Data collection from the households was done from the homes following prior appointments. The interviews were conducted in the local language Turkana, English and Kiswahili. A structured questionaire was used for data compilation. Filled questionnaires were checked for completeness on daily basis and the principal investigator ensured during the whole period of data collection that the questionnaires were reviewed and checked for completeness and consistency. Data entry was made by EpiData statistical software to ensure double entry verification so as to minimize error.

\subsection{Data Management and Analysis}

Data from the questionnaires was coded and entered into a spreadsheet and the database. The data was double entered in Access, cleaned in Epinfo and quantitative data analysed using the regression and correlation, multi-variate analysis with the use of Software statistical Package for Social Sciences (SPSS) [13]. Qualitative data was analysed thematically. Analytical techniques were used depending on the type of data and the variables to be analyzed. Independent and the dependent variables were compared using Chisquare, where a probability value of $p<0.005$ at $95 \%$ confidence interval, were considered significant [13]. Descriptive statistics such as frequencies, line graphs, pie charts and bar graphs, were used to describe, organize and summarize the data.

\subsection{Ethical Considerations}

Clearance for the study was obtained from Scientific and Ethical Review Unit (SERU) in KEMRI, Jomo Kenyatta University, Ministry of Health and Ministry of Education. 
Further permission was sought from the Provincial administration Turkana county and Loima sub-county, household heads and the community leaders. The purpose of the study was clearly explained to the participants while requesting them to sign informed consent forms as a sign of willingness.

\section{Results}

Social Demographic Characteristics and Socio-Economic Factors of the Study Subjects

The results of the study have shown that 171 (50.1\%) of the subjects interviewed were in the age category $18-35,129$ $(37.8 \%)$ were in the age category $36-49,38(11.1 \%)$ were in the category of $50-70$ years, while only $3(0.9 \%)$ were in the age category of above years (Table 1). Slightly over 181 $(53.1 \%)$ of those interviewed were females while 160 (46.9\%) were males.

A high proportion of $294(86.2 \%)$ of the respondents were married while $47(13.8 \%)$ were single, widowed or divorced.
With regards to religion, 206(60.4\%) were Catholics, 86 $(25.2 \%)$ Protestants, $35(10.3 \%)$ were traditionalists while Muslims, Jehovah Witness and the SDA constituted 7 (2.1),4 $(1.2 \%)$ and $3(0.9 \%)$, respectively (Table 1). A majority, 193 $(56.7 \%)$ of the respondents had no formal education, about $70(20.5 \%)$ had obtained primary education, $45(13.2 \%)$ secondary education while $33(9.6 \%)$ had college/ university education. With respect to occupation, $210(61.6 \%)$ were livestock keepers (herdsmen), 41 (12.0\%) were in business, $34 \quad(9.9 \%)$ were farmers, $73 \quad(16.5 \%)$ were either administrators, teachers, health workers or being house wife. A larger number $211(61.9 \%)$ of the respondents were unemployed, 98 (28.7\%) were self-employed while only a small proportion of $32(9.4 \%)$ were employed. Majority of the respondents $218(61.9 \%)$ had livestock keeping as their source of income while $123(38.1 \%)$ had their source being either business, farming or formal employment, with many of them-203 (59.5\%) living in rural areas, $126(37 \%)$ in periurban while only a small proportion of $12(3.5 \%)$ live in urban area of Loima Sub-county (Table 1).

Table 1. Socio-demographic factors that predispose the community to Kala-azar $(N=341)$.

\begin{tabular}{|c|c|c|c|c|c|}
\hline \multicolumn{2}{|c|}{ Social Demographic Factors } & \multicolumn{4}{|c|}{ Community predisposed to Kala-azar } \\
\hline & & \multirow{2}{*}{$\begin{array}{l}\text { Yes } \\
n(\%)\end{array}$} & \multirow{2}{*}{$\begin{array}{l}\text { No } \\
\text { n (\%) }\end{array}$} & \multicolumn{2}{|l|}{ Odds Ratio } \\
\hline & Overall n(\%) & & & $(95 \% \mathrm{CI})$ & P values \\
\hline \multicolumn{6}{|l|}{ Age } \\
\hline $18-35$ & $171(50.1)$ & $99(57.8)$ & $72(42.2)$ & Ref & \\
\hline $36-49$ & $129(37.8)$ & $62(48.4)$ & $66(51.6)$ & $0.7(0.4-1.1)$ & 0.135 \\
\hline $50-70$ & $38(11.1)$ & $15(40.0)$ & $23(60.0)$ & $0.7(0.3-1.3)$ & 0.249 \\
\hline Above 70 years & $3(0.9)$ & $1(33.3)$ & $2(66.7)$ & $1.3(0.1-14.8)$ & 0.822 \\
\hline \multicolumn{6}{|l|}{ Gender } \\
\hline Male & $160(46.9)$ & 101(63.1) & $59(36.9)$ & Ref & \\
\hline Female & 181(53.1) & $73(40.2)$ & $108(59.8)$ & $0.6(0.4-0.9)$ & 0.012 \\
\hline \multicolumn{6}{|l|}{ Marital status } \\
\hline Married & $294(86.2)$ & $133(45.4)$ & $160(54.6)$ & Ref & \\
\hline Unmarried & $35(10.3)$ & $11(31.4)$ & $24(68.6)$ & $1.8(0.9-3.8)$ & 0.120 \\
\hline Widowed & $10(2.9)$ & $6(60.0)$ & $4(40.0)$ & $0.6(0.2-2.0)$ & 0.368 \\
\hline Divorced & $2(0.6)$ & $0(0.0)$ & $2(100.0)$ & NA & 0.999 \\
\hline \multicolumn{6}{|l|}{ Education level } \\
\hline No education & 193(56.7) & $125(65.0)$ & $68(35.0)$ & Ref & \\
\hline Primary & $70(20.5)$ & $39(56.4)$ & $31(43.6)$ & $1.2(0.7-2.4)$ & 0.501 \\
\hline Secondary & $45(13.2)$ & $18(41.0)$ & $27(59.0)$ & $4.9(1.9-12.2)$ & 0.001 \\
\hline College/university & $33(9.7)$ & $10(29.2)$ & 23(70.8) & $3.9(1.6-9.3)$ & 0.002 \\
\hline \multicolumn{6}{|l|}{ Religion } \\
\hline Roman Catholic & $205(60.1)$ & $91(44.6)$ & $113(55.4)$ & Ref & \\
\hline Protestant & $86(25.2)$ & $36(41.9)$ & $50(58.1)$ & $1.1(0.7-1.9)$ & 0.667 \\
\hline Jehovah Witness & $4(1.2)$ & $1(25.0)$ & $3(75.0)$ & $2.4(0.2-23.6)$ & 0.448 \\
\hline Traditionalist & $36(10.6)$ & $19(52.8)$ & $17(47.2)$ & $0.7(0.4-1.5)$ & 0.366 \\
\hline SDA & $3(0.9)$ & $1(33.3)$ & $2(66.7)$ & $1.6(0.1-18.0)$ & 0.699 \\
\hline Muslim & $7(2.1)$ & $2(28.6)$ & $5(71.4)$ & $2.0(0.4-10.6)$ & 0.410 \\
\hline \multicolumn{6}{|l|}{ Residence } \\
\hline Urban & $12(3.5)$ & $5(38.0)$ & $7(62.0)$ & Ref & \\
\hline Peri-urban & $127(37.2)$ & $70(55.0)$ & $57(45.0)$ & $0.6(0.2-2.3)$ & 0.46 \\
\hline Rural & $202(59.2)$ & $119(59.0)$ & $83(41.0)$ & $0.3(0.1-1.2)$ & 0.101 \\
\hline
\end{tabular}

The results in table 1 show the association between the respondents being predisposed to Kala-azar and sociodemographic factors. The results indicated that age was a factor in being exposed to kala-azar such that amongst those who were more predisposed, $57.8 \%(\mathrm{n}=99)$ were of the ages between $18-35$ years compared to $48.4 \%(\mathrm{OR}=0.7 ; 95 \% \mathrm{CI}=$ $(0.4-1.1), \mathrm{p}=0.135)$ of the ages between $36-49$ years, $40 \%$
$(\mathrm{OR}=0.7 ; 95 \% \mathrm{CI}=(0.3-1.3), \mathrm{p}=0.249)$ of ages between $50-70$ years or $33.3 \%(\mathrm{OR}=1.3 ; 95 \% \mathrm{CI}=(0.1-1.48), \mathrm{p}=0.822)$ of above 70 years. The results showed that among the gender of the respondents exposed, 63.1\% $\quad(n=59)$ were males compared to $40.2 \%(n=91)$ females. Males were more likely to be predisposed to Kala-azar compared to females $(\mathrm{OR}=0.6 ; 95 \% \mathrm{CI}=(0.4-0.9), \mathrm{p}=0.012$. Of those who had no 
education $(n=125), 65.0 \%$ of them were predisposed to Kalaazar compared to $41.0 \% \quad(\mathrm{OR}=4.9 ; 95 \% \mathrm{CI}=(1.9-12.2)$, $\mathrm{p}=0.001)$ of those with secondary education or $29.2 \%$ $(\mathrm{OR}=3.9 ; \quad 95 \% \mathrm{CI}=(1.6-9.3), \quad \mathrm{p}=0.002)$ of those with college/university education. The differences in proportions were statistically significant compared to those who had no education. Respondents who had no formal education were more at risk for they had no proper knowledge on control or even the transmission of Kala-azar which is by bites of sand flies while those who had attained beyond form level of education were knowledgeable hence least predisposed. The respondents $38 \%(n=5)$ living in urban area were less likely to be predisposed to the disease as compared to $55 \%$ $(\mathrm{OR}=0.6 ; 95 \% \mathrm{CI}=(0.2-2.3), \mathrm{p}=0.46)$ of those living in periurban and $59 \%(\mathrm{OR}=0.3 ; 95 \% \mathrm{CI}=(0.1-1.2), \mathrm{p}=0.101)$. There was no statistical significance in the association between the socio-demographic factors (marital status and religion) and being predisposed to Kala-azar.

Table 2. Socio-economic factors that predispose the community to Kala-azar.

\begin{tabular}{|c|c|c|c|c|c|}
\hline \multirow[t]{3}{*}{ Socio-economic factors } & \multicolumn{4}{|c|}{ Community predisposed to Kala-azar } & \multirow[b]{3}{*}{ P values } \\
\hline & & Yes & No & Odds Ratio & \\
\hline & Overall n(\%) & n (\%) & n (\%) & $(95 \% \mathrm{CI})$ & \\
\hline \multicolumn{6}{|l|}{ Employment } \\
\hline Employed & $71(20.8)$ & $16(21.9)$ & $55(78.1)$ & $2.5(1.0-6.2)$ & 0.057 \\
\hline Unemployed & $172(50.5)$ & $103(61.0)$ & $107(39.0)$ & $0.7(0.4-1.2)$ & 0.178 \\
\hline \multicolumn{6}{|l|}{ Occupation } \\
\hline Livestock keeper & $181(53.1)$ & $97(63.4)$ & $112(36.6)$ & $2.5(1.2-5.4)$ & 0.018 \\
\hline Teacher & $35(10.3)$ & $10(28.6)$ & $25(71.4)$ & $5.5(1.7-17.9)$ & 0.005 \\
\hline Health worker & $10(2.9)$ & $3(25.0)$ & $7(75.0)$ & $6.5(0.6-65.2)$ & 0.121 \\
\hline Administrator & $25(7.3)$ & $10(40.1)$ & $15(59.9)$ & $13.1(1.4-120.2)$ & 0.024 \\
\hline Business man & $41(12.0)$ & $18(45.0)$ & $23(55.0)$ & $4.7(1.8-12.4)$ & 0.002 \\
\hline Other e.g house wife & $15(4.4)$ & $5(34.8)$ & $10(65.2)$ & $4.1(1.3-12.5)$ & 0.013 \\
\hline \multicolumn{6}{|l|}{ Source of income } \\
\hline Farming & $35(10.3)$ & $18(60.0)$ & $12(40.0)$ & Ref & \\
\hline Formal employment & $70(20.5)$ & $15(21.7)$ & $55(78.3)$ & $5.4(1.6-18.5)$ & 0.007 \\
\hline Business & $43(12.6)$ & $18(40.7)$ & $25(59.3)$ & $2.7(1.0-6.7)$ & 0.033 \\
\hline Other e.g selling of local brew & $14(4.1)$ & $5(39.1)$ & $9(60.9)$ & $9.0(1.7-47.6)$ & 0.010 \\
\hline \multicolumn{6}{|l|}{ Economic activity } \\
\hline Farming/agriculture & $38(11.1)$ & $16(41.2)$ & $22(58.8)$ & Ref & \\
\hline Livestock & $203(59.5)$ & $127(62.4)$ & $76(37.6)$ & $0.9(0.3-2.4)$ & 0.792 \\
\hline Farming \& livestock & $75(22.0)$ & $39(52.0)$ & $36(48.0)$ & $2.4(1.4-3.7)$ & 0.869 \\
\hline Other e,g burning charcoal & $25(7.3)$ & $16(64.0)$ & $9(36.0)$ & $7.0(2.1-3.8)$ & 0.0542 \\
\hline \multicolumn{6}{|l|}{ Housing } \\
\hline Grass-thatched & $186(54.6)$ & $127(63.9)$ & $144(36.1)$ & Ref & \\
\hline Modern mabati/semi-permanent & $115(33.7)$ & $55(48.1)$ & $60(51.9)$ & $1.8(1.0-3.1)$ & 0.029 \\
\hline Stone-built/permanent & $40(11.3)$ & $14(35.8)$ & $26(64.2)$ & $0.6(0.1-10.2)$ & 0.729 \\
\hline \multicolumn{6}{|l|}{ Housing roofing } \\
\hline Grass-thatched & $185(54.3)$ & $108(58.5)$ & $77(41.5)$ & Ref & \\
\hline Iron sheets & $116(34.0)$ & $45(38.7)$ & $71(61.3)$ & $0.7(0.5-2.4)$ & 0.004 \\
\hline Mud & $185(54.3)$ & $126(68.0)$ & $59(32.0)$ & Ref & \\
\hline Semi-permanent & $115(33.7)$ & $61(53.4)$ & $54(46.6)$ & $1.4(1.2-2.6)$ & 0.047 \\
\hline Parmanent & $41(12.0)$ & $15(36.0)$ & $26(64.0)$ & $0.6(0.4-1.8)$ & 0.354 \\
\hline \multicolumn{6}{|l|}{ House floor } \\
\hline Mud & $156(45.7)$ & $117(75.0)$ & $39(25.0)$ & Ref & \\
\hline Wooden & $85(25.0)$ & $47(55.0)$ & $38(45.0)$ & $0.8(0.7-1.8)$ & 0.0346 \\
\hline Cement & $70(20.5)$ & $24(34.0)$ & $46(66.0)$ & $1.2(1.4-2.2)$ & 0.0793 \\
\hline Tiles & $30(8.8)$ & $10(33.3)$ & $20(66.7)$ & $4.5(2.1-3.8)$ & 0.8991 \\
\hline \multicolumn{6}{|l|}{ Level of income } \\
\hline$<$ Kshs 1,000 Between Kshs 2000 & $93(27.3)$ & $61(66.0)$ & $32(34.0)$ & Ref & \\
\hline -Kshs 5000. Between Kshs 5001 & $75(22.0)$ & $7(49.0)$ & $38(51.0)$ & $2.3(0.1-1.4)$ & 0.0042 \\
\hline -Kshs 10,000 Between Kshs 10,001 & $63(18.5)$ & $23(37.0)$ & $40(63.0)$ & $0.6(0.1-7.3)$ & 0.2313 \\
\hline -Kshs 15000 & $60(17.6)$ & $15(25.0)$ & $45(75.0)$ & $0.7(1.1-2.5)$ & 0.2653 \\
\hline$>$ Kshs 15,000 & $50(14.6)$ & $15(30.0)$ & $35(70.0)$ & $.4(1.5-3.4)$ & 0.0658 \\
\hline
\end{tabular}

Results in table 2 show the association between being predisposed to Kala-azar and socio-economic factors. The results revealed that $63.4 \%(n=97)$ of those who engaged in livestock keeping, or $28.6 \%(\mathrm{n}=10)$ who were teachers,
$40.1 \%(\mathrm{n}=10)$ who were administrators, $45.0 \%(\mathrm{n}=18)$ who were business men or $34.8 \%(n=5)$ who had other forms of occupation were predisposed to Kala-azar compared to $60.6 \%(n=24)$ who were farmers. The results further revealed 
that $21.7 \% \quad(n=5)$ of the respondents who had formal employment as their main source of income or $39.1 \%(n=5)$ of those who had other sources of income were predisposed to Kala-azar compared to $60 \%(n=18)$ whose main source of income was farming. The results further showed that housing including the type of house wall, floor and roofing had an impact on being exposed to the disease. Respondents $63.9 \%$ $(n=127)$ who had grass-thatched house were more predisposed to kala-azar as compared to $48.1 \% \quad(n=55)$ $(\mathrm{OR}=1.8 ; 95 \% \mathrm{CI}=(1.0-3.1), \mathrm{p}=0.029)$ of semi-permanent house and $35.8 \% \mathrm{n}=14, \quad(\mathrm{OR}=0.6 ; 95 \% \mathrm{CI}=(0.1-10.2)$, $\mathrm{p}=0.729$ ) of permanent house. Respondents with house roofing being grass-thatched; wall and floor made of mud, 58.5\% $\quad(n=108), \quad 68 \%(n=126) \quad$ and $75 \% \quad(n=117)$ respectively, were more predisposed to the disease as compared to those whose houses roofing were of iron sheets $38.7 \%(n=45)$, house wall being semi-permanent $53.4 \%(n=61)$ or permanent $36 \%(n=15)$ and floor being of wood $55 \%(n=47)$, cement $34 \%(n=24)$ or of tiles $33.3 \%(n=10)$. The results also revealed that respondents $66 \%$ $(n=61)$ whose level of income was below Kshs 1,0000,were more exposed to kala-azar as compared to $49 \%(n=37)$ $(\mathrm{OR}=2.3 ; 95 \% \mathrm{CI}=(0.1-1.4), \mathrm{p}=0.0042)$. those of between Kshs 2,000-Kshs 5,000, 37\%(n=23) $(\mathrm{OR}=0.6$; 95\%CI $=(0.1-$ 7.3), $\mathrm{p}=0.2313)$., of between Kshs 5001-Kshs $10,000,25.0 \%(\mathrm{n}=15)(\mathrm{OR}=0.7 ; 95 \% \mathrm{CI}=(1.1-2.5), \mathrm{p}=0.2653)$. of between Kshs 10,001-Kshs 15,000 and 30.0\%(n=15), $(\mathrm{OR}=1.4 ; 95 \% \mathrm{CI}=(1.5-3.4), \mathrm{p}=0.0658)$, those $>$ Kshs 15,000 . The differences in proportions due to housing and the level of income were statistically significant for exposure or being predisposed to the disease, because the grass thatched and semi-permanent houses built using sticks and mud have cracks that can be Kala-azar vector habitant hence breeding site for the sand fly as the disease is linked to poverty, poor sanitation and sub-standard housing.

Table 3. Socio-cultural factors that predispose the community to Kala-azar.

\begin{tabular}{|c|c|c|c|c|c|}
\hline \multirow[t]{3}{*}{ Socio-cultural factors } & & \multicolumn{3}{|c|}{ Community predisposed to Kala-azar } & \multirow[b]{3}{*}{ P values } \\
\hline & & Yes & No & Odds Ratio & \\
\hline & Overall n(\%) & n (\%) & n (\%) & $(95 \% \mathrm{CI})$ & \\
\hline \multicolumn{6}{|l|}{ Human activities encouraging disease spread } \\
\hline Deforestation & $84(24.6)$ & $43(51.0)$ & $41(49.0)$ & Ref & \\
\hline Agriculture/Peasant farming & $21(6.2)$ & $9(44.0)$ & $12(56.0)$ & $0.6(0.1-5.1)$ & 0.641 \\
\hline Hunting & $40(11.7)$ & $21(53.1)$ & $19(46.9)$ & $2.0(0.3-13.7)$ & 0.481 \\
\hline Gold & $3(0.9)$ & $1(33.3)$ & $2(66.7)$ & $1.3(0.1-2.4)$ & 0.870 \\
\hline Military service & $5(1.5)$ & $2(40.0)$ & $3(60.0)$ & $1.2(0.1-19.6)$ & 0.898 \\
\hline Livestock keeping & $188(55.1)$ & $127(67.6)$ & $61(32.4)$ & $0.7(0.2-2.9)$ & 0.004 \\
\hline \multicolumn{6}{|l|}{ Cultural activities } \\
\hline Polygamy & $19(5.6)$ & $4(30.8)$ & $9(69.2)$ & Ref & \\
\hline Dancing at night(Edong'a) and overgrazing & $258(75.6)$ & $167(64.8)$ & $91(35.2)$ & $0.5(0.2-1.7)$ & 0.006 \\
\hline Early marriage & $17(5.0)$ & $1(8.3)$ & 16(91.7) & $4.9(0.5-51.9)$ & 0.188 \\
\hline Drinking animal blood & $47(13.8)$ & $24(20.0)$ & $23(80.0)$ & $0.4(0.1-1.6)$ & 0.205 \\
\hline \multicolumn{6}{|l|}{ Why the people are exposed to kala-azar } \\
\hline Because of their daily activities or occupation & $93(27.2)$ & $60(63.0)$ & $33(37.0)$ & Ref & \\
\hline Their encounter with sand flies & $220(64.5)$ & $180(72.0)$ & $40(28.0)$ & $0.6(2.0-3.4)$ & 0.0045 \\
\hline lack of knowledge about the disease & $20(5.9)$ & $8(51.9)$ & $12(48.1)$ & $1.2(0.1-2.1)$ & 0.0033 \\
\hline Their relationship with dogs & $8(2.3$ & $2(25.0)$ & $6(75.0)$ & $0.7(2.4-40.7)$ & 0.0542 \\
\hline \multicolumn{6}{|l|}{ Respondents time of sleep } \\
\hline Between 8 p.m-9 p.m. & $150(44.0 \%)$ & $60(42.5)$ & $90(57.5)$ & Ref & \\
\hline 9.30 p.m-10.30 p.m & $72(21.1 \%)$ & $35(48.3)$ & $37(51.7)$ & $0.6(0.1-2.8)$ & 0.04531 \\
\hline $9.31-11.30$ p.m & $78(22.9 \%)$ & $40(51.0)$ & $38(49.0)$ & $0.6(1.1-2.4)$ & 0.6543 \\
\hline Beyond 11.30 p.m & $41(12.0 \%)$ & $25(60.0)$ & $16(40.0)$ & $1.4(1.3-4.0)$ & 0.4631 \\
\hline \multicolumn{6}{|l|}{ Practice or behaviour predisposing to the disease } \\
\hline $\begin{array}{l}\text { Resting, playing or sitting near the termite mounts } \\
\text { oftenly }\end{array}$ & $273(80.2 \%)$ & 191(70.0) & $82(30.0)$ & Ref & \\
\hline Resting or sleeping near the animal homesteads & $35(10.8 \%)$ & $17(48.0)$ & $18(52.0)$ & $0.6(0.1-2.1)$ & 0.0043 \\
\hline Sleeping close to goatherds & $33(9 \%)$ & $13(39.0)$ & $20(61.0)$ & $0.7(1.6-2.9)$ & 0.0023 \\
\hline \multicolumn{6}{|l|}{$\begin{array}{l}\text { Treatment given to somebody when sick of kala- } \\
\text { azar in the community }\end{array}$} \\
\hline Smear of cow dung to the affected area & $44(12.9)$ & $27(53.0)$ & $17(47.0)$ & Ref & \\
\hline No treatment, but taken to the hospitals & $124(36.4)$ & $30(24.0)$ & $94(76.0)$ & $0.6(1.1-2.3)$ & 0.0563 \\
\hline $\begin{array}{l}\text { Use of traditional herbs around or given by } \\
\text { traditional healers }\end{array}$ & $140(41.1)$ & $99(71.0)$ & $41(29.0)$ & $1.1(0.1-3.3)$ & 0.0042 \\
\hline $\begin{array}{l}\text { Making of an incision to the affected area (spleen) } \\
\text { or stomach and drawing out blood }\end{array}$ & $33(9.6)$ & $24(73.0)$ & $9(27.0)$ & $0.6(2.2-3.4)$ & 0.0040 \\
\hline
\end{tabular}

The results in table 3 showed that the respondents or the community members that carry out the human activities of livestock keeping $67.6 \%(\mathrm{n}=127)(\mathrm{OR}=0.7 ; 95 \% \mathrm{CI}=(0.2-$ $2.9), \mathrm{p}=0.004)$, hunting $53.1 \%(\mathrm{n}=21),(\mathrm{OR}=2.0 ; 95 \% \mathrm{CI}=$
$(0.3-13.7), p=0.481)$ and deforestation $51 \%(n=43)$, were more predisposed to kala-azar as compared to peasant farming $44 \%(n=9)$, military service $40 \%(n=2)$ or gold extraction $33.3 \%(n=1)$. There was a statistical association between the 
human activity of livestock keeping and being exposed to kala-azar $(\mathrm{OR}=0.7 ; 95 \% \mathrm{CI}=(0.2-2.9), \mathrm{p}=0.004)$.

The results revealed that the practice of cultural activities of dancing at night (Edong'a) and deforestation $64.8 \%(\mathrm{n}=167$ $\mathrm{OR}=2.0 ; 95 \% \mathrm{CI}=(0.3-13.7), \mathrm{p}=0.481)$ could be more an exposure to kala-azar than polygamy $30.8 \%(n=4)$ early marriages $8.3 \%(n=1)$ or drinking of animal blood during dry season $20 \%(n=24)$ which had no statistical significance in the association with being predisposed to Kala-azar.

The results showed that the respondents or community's members often encounter with sand flies $72 \%(n=180)$, their daily activities or occupation $63 \%(\mathrm{n}=60) \mathrm{OR}=0.6 ; 95 \% \mathrm{CI}=$ (1.3-4.2), $\mathrm{p}=0.0033)$ exposes them more to the disease as compared to lack of knowledge about it $51.9 \%(n=8) O R=1.2$; $95 \% \mathrm{CI}=(0.1-2.1), \mathrm{p}=0.0045)$ and their relationship with dogs $25 \%(n=2) \quad O R=0.7 ; 95 \% \mathrm{CI}=(2.4-40.7), \mathrm{p}=0.0542)$. The difference in proportions were statistically significant compared to the relationship with dogs.

The respondents time of sleep beyond $11.30 \mathrm{pm}$ $60 \%(n=25), 9.30-11.30 \mathrm{pm} 51 \%(n=40)$ exposed them to the disease as compared to sleeping between $9.30 \mathrm{pm}-10.30 \mathrm{pm}$ $48.3 \%(\mathrm{n}=35)$ and time between $8 \mathrm{pm}-9 \mathrm{pm} 42.5 \%(\mathrm{n}=60)$. The sand flies ( Kala-azar vector) are active during all these times, hence the people are at risk daily, thus the need to always use insecticide treated bed nets and other preventive measures.

The behaviour or practice of resting,playing or sitting near termite mounds oftenly $(70 \%(\mathrm{n}=191)$, resting or sleeping near the animal homesteads $48 \%(n=17) \mathrm{OR}=0.6 ; 95 \% \mathrm{CI}=(0.1-2.1)$, $\mathrm{p}=0.0043$ ) exposed the respondents more to kala-azar as compared to sleeping close to goatherds $39 \%(n=13)$ OR $=0.7$; $95 \% \mathrm{CI}=(1.6-2.9), \mathrm{p}=0.0023)$. There was a significant statistical association between these behaviours or practices and being predisposed to kala-azar. The results also revealed that the respondents' or community members practice of making of incision to the affected area (spleen) or stomach and drawing out blood as a form of treatment $73 \%(n=24) \mathrm{OR}=0.6 ; 95 \% \mathrm{CI}=(2.2-$ 3.4), $\mathrm{p}=0.0040)$, Use of traditional herbs around or given by traditional healers $71 \%(\mathrm{n}=99) \quad \mathrm{OR}=1.1 ; 95 \% \mathrm{CI}=(0.1-3.3)$, $\mathrm{p}=0.0042$ ), exposes more to the disease as compared to smear of cow-dung to the affected area $53 \%(\mathrm{n}=27)$ and going straight to the hospital when sick of kala-azar without first going through the traditional healers $24 \%(\mathrm{n}=30) \mathrm{OR}=0.6 ; 95 \% \mathrm{CI}=(1.1-2.3)$, $\mathrm{p}=0.0563)$. The difference in proportions were statistically significant as compared to the sick being taken to hospital without first going through traditional healers; and that the results on treatment given to somebody when sick of kala-azar, showed that preference for alternative treatments influences the health seeking behavior in the community and thus more exposure to the disease.

Table 4. Prevalence of Kala-azar in Loima sub-county.

\begin{tabular}{|c|c|c|c|c|c|}
\hline \multirow[t]{3}{*}{ Exposure to Kala-azar } & \multicolumn{5}{|c|}{ Community predisposed to Kala-azar } \\
\hline & \multicolumn{2}{|r|}{ Yes } & \multirow{2}{*}{$\begin{array}{l}\text { No } \\
\text { n (\%) }\end{array}$} & \multicolumn{2}{|l|}{ Odds Ratio } \\
\hline & Overall n (\%) & n (\%) & & $(95 \% \mathrm{CI})$ & P values \\
\hline Mostly affected groups & Mostly affected groups & & & & \\
\hline Males & $53(15.7)$ & $28(52.8)$ & $25(47.2)$ & Ref & \\
\hline Females & $11(3.3)$ & $4(36.4)$ & $7(63.6)$ & $1.6(0.4-6.0)$ & 0.514 \\
\hline Males \& females & $273(81.0)$ & $119(43.8)$ & $153(56.3)$ & $1.1(0.6-2.1)$ & 0.647 \\
\hline \multicolumn{6}{|l|}{ Groups at risk } \\
\hline Young girls & $24(7.3)$ & $15(62.5)$ & $9(37.5)$ & $0.5(0.2-1.1)$ & 0.078 \\
\hline Female youth & $7(2.1)$ & $2(28.6)$ & $5(71.4)$ & $1.9(0.4-10.1)$ & 0.441 \\
\hline Male youth & $40(12.1)$ & $21(52.5)$ & $19(47.5)$ & $0.8(0.4-1.7)$ & 0.630 \\
\hline Adult male & $1(0.3)$ & $0(0.0)$ & $1(100.0)$ & NA & 1.000 \\
\hline Adult female & $1(0.3)$ & $0(0.0)$ & $1(100.0)$ & NA & 1.000 \\
\hline \multicolumn{6}{|c|}{ Common diseases in the area } \\
\hline Malaria & $126(37.0)$ & $38(30.0)$ & $88(70.0)$ & Ref & Ref \\
\hline Kala-azar & $60(17.6)$ & $44(73.7)$ & $16(26.3)$ & $1.2(1.1-2.6)$ & 0.0025 \\
\hline Typhoid & $35(10.3)$ & $12(33.0)$ & $23(67.0)$ & $0.5(0.1-2.1)$ & 0.765 \\
\hline Brucella & $35(10.3)$ & $11(31.0)$ & $24(69.0)$ & $0.6(0.2-2.3)$ & 0.432 \\
\hline HIV/AIDS & $40(11.6)$ & $18(45.0)$ & $22(55.0)$ & $0.7(0.1-2.2)$ & 0.344 \\
\hline \multicolumn{6}{|c|}{ If kala-azar is a common disease in the area } \\
\hline Yes & $263(77.0)$ & $121(46.0)$ & $162(54.0)$ & Ref & Ref \\
\hline No & $78(23.0)$ & $42(54.0)$ & $36(46.0)$ & $0.6(2.0-3.0)$ & 0.456 \\
\hline \multicolumn{6}{|c|}{ If respondent member of family has ever suffered kala-azar } \\
\hline Yes & $280(82)$ & $174(62.0)$ & $106(38.0)$ & Ref & Ref \\
\hline No & $61(18)$ & $40(65.0)$ & $21(35.0)$ & $0.6(2.0-2.5)$ & 0.054 \\
\hline \multicolumn{6}{|c|}{ If respondent ever suffered kaka-azar } \\
\hline Yes & $151(44.3)$ & $74(49.0)$ & $77(51.0)$ & Ref & Ref \\
\hline No & $190(55.7)$ & $80(42.0)$ & $110(58.0)$ & $0.5(0.1-2.1)$ & 0.642 \\
\hline \multicolumn{6}{|c|}{ What encourages kala-azar to spread } \\
\hline Drought & $13(3.8)$ & $7(51.7)$ & $6(48.3)$ & Ref & Ref \\
\hline Lack of medical facilities & $51(15)$ & $28(54.0)$ & $23(46.0)$ & $0.5(0.2-4.0)$ & 0.0545 \\
\hline
\end{tabular}




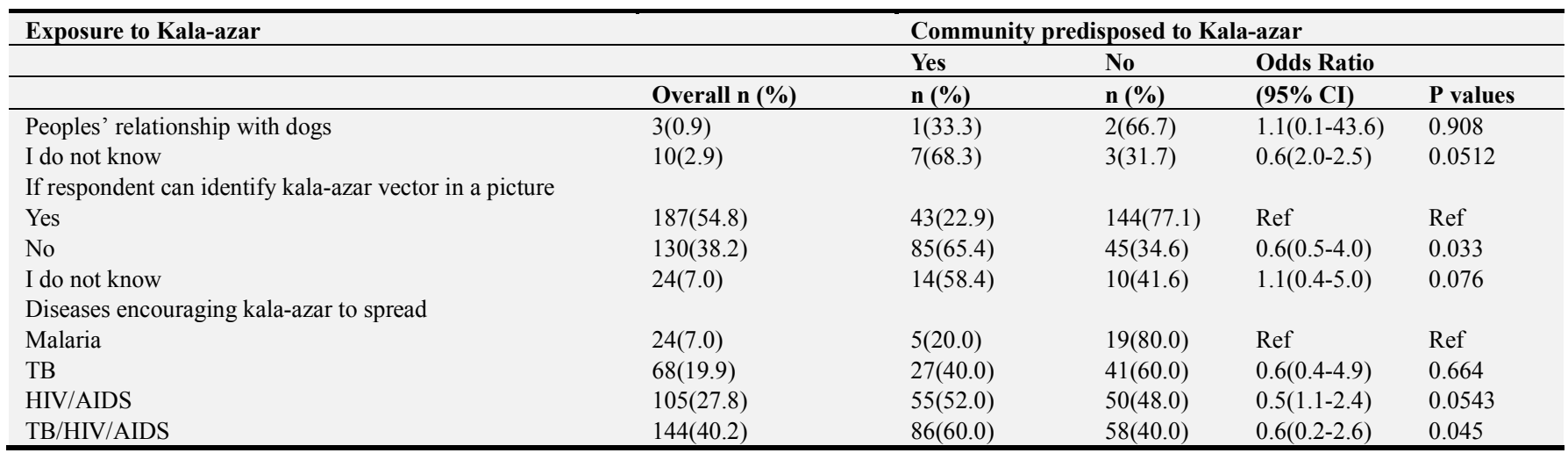

The main factors that were used to determine the prevalence of Kala-azar in Loima sub-county were classified as exposure factors. These included the mostly affected groups and those groups that were considered to be at risk.

Table 4 shows the association between those exposure factors and being predisposed to Kala-azar. The results showed that the males $52.8 \%(\mathrm{n}=28)$ are the mostly affected gender and that young boys $56.6 \%(\mathrm{n}=142)$ as compared to other groups due to their behaviour, practices, daily activities or occupation. The results showed that among the top priority and prevalent diseases in the area as indicated, Kala-azar is the $2^{\text {nd }}$ prevalent parasitic disease $17.6 \%(n=60)$ after malaria $37.0 \%(\mathrm{n}=126)$. Kala-azar according to the medical records and key informant interviews, is the most neglected tropical disease in the area and more people are predisposed $73.7 \%(\mathrm{n}=44) \mathrm{OR}=1.2 ; 95 \% \mathrm{CI}=(1.1-2.6), \mathrm{p}=0.0025)$.

The results revealed that majority of the respondents that mentioned that kala-azar is not a common disease in the area were likely to be exposed to it $54 \%(\mathrm{n}=42) \mathrm{OR}=0.6 ; 95 \% \mathrm{CI}=$ (2.0--3.0), $\mathrm{p}=0.0456$ ), as compared to those who said the disease is common in the area $46 \%(n=121)$. The respondents member of family who had not suffered kala-azar according to the results, were more likely to be exposed by $65 \%(n=40)$ as compared to those who had suffered $62 \%(n=174)$. The results also indicated that the respondents who ever suffered kala-azar, were more at risk of its exposure $49 \%(n=74)$ as compared to those who had not suffered $42 \%(\mathrm{n}=80) \mathrm{OR}=0.5$; $95 \% \mathrm{CI}=(0.1--2.1), \mathrm{p}=0.642)$.

The results also revealed that the presence of ant-hills $77.4 \%(\mathrm{n}=159) \mathrm{OR}=0.6 ; 95 \% \mathrm{CI}=(0.2--2.0), \mathrm{p}=0.0045)$, lack of knowledge on disease spread $68.3 \%(n=7) \quad \mathrm{OR}=0.6$; $95 \% \mathrm{CI}=(0.2--2.5), \mathrm{p}=0.0512)$, lack of medical facilities $54 \%(\mathrm{n}=28) \quad \mathrm{OR}=0.5 ; 95 \% \mathrm{CI}=(0.2--4.0), \mathrm{p}=0.0545)$, was more predisposing to the disease as compared to cattle keeping activity $53.5 \%(\mathrm{n}=32) \mathrm{OR}=1.1 ; 95 \% \mathrm{CI}=(0.1--2.2)$, $\mathrm{p}=0.0641)$,drought $51.7 \%(\mathrm{n}=7)$ and peoples' relationship with dogs $33.3 \%(n=1) \quad \mathrm{OR}=1.1 ; \quad 95 \% \mathrm{CI}=(0.1--43.6)$, $\mathrm{p}=0.908$ ).

The results also indicated that among the respondents that could identify kala-azar vector in a photo, $22.9 \%(n=43)$ were less likely to be predisposed to the disease as compared to those who could not $65.4 \%(\mathrm{n}=85)$ or even did not have any knowledge on the identification $58.4 \%(n=14) \quad \mathrm{OR}=1.1$; $95 \% \mathrm{CI}=(0.4-5.0), \mathrm{p}=0.076)$. The results further indicated that the TB/HIV/AIDS $60 \% \quad(n=86)$ or even other opportunistic infections combination could be the diseases that mostly encourage the spread of the dreadful disease kalaazar in the area. The results are supported by key informant interviews, focus group discussions and medical records that indicate kala-azar is now becoming an AIDS defining disease.

\section{Discussions}

The results showed that age is a factor with regard to exposure and susceptibility to Kala-azar, with age groups between 5-29 years being hardly hit, but especially 15 years being the most at risk (by $60 \%$ ). It has been demonstrated that males are more at risk due to their occupation or their daily activities which often bring them into contact with termite mounds, that are kala-azar habitat. This observation concurs with other studies $[10,15]$, which have noted that males are three times more susceptible to kala-azar than females. An epidemiological systematic review and metaanalysis done in America to assess factors associated with Visceral Leishmaniasis (VL) also revealed that the male sex was significantly associated with the infection, with the ORs of 1.30 and 2.38 [4]. A similar study on factors associated with Visceral leishmaniasis infection in North Gondar zone, Amhara region, North West Ethiopia by Kindie Bantie et $a l ; 2014$ [2], revealed that age and gender were significantly associated with increased risk of Visceral leishmaniasis (VL) infection; such that children less than 15 years were 3.3 times more likely to be infected with VL than adults who were aged 15 years and above $(\mathrm{AOR}=3.26 ; 95 \% \mathrm{CI}=1.54,56.92)$; and that males were about 4.6 times more likely to be infected with kala-azar than females $(\mathrm{AOR}=4.64$; $95 \% \mathrm{CI}=2.39,9.39$ ). The male gender predominance of the infection could be due to the reason that males are mostly engaged in outdoor activities and stay outdoor from dawn to dusk that might increase their contact with sand fly and in most rural parts of our country like Loima, men are mostly forced to sleep outside to keep their cattle and other valuables from theft. A study done in Trishal Upazila, Bangladesh demonstrated a significant association between VL and different age groups [16]. Another study done in Nepal also indicated that age is associated with increased risk of infection [17]. A study done in South Sudan also indicated 
that the peak age group for VL infection was under the age of three years old [18]. The possible justification for this age based predominance could be due to the reason that children whose age is below 15 years are less developed immune system and most of them would not have previous attack with VL which could make them partially immune after getting infected with the disease commonly observed in areas with sustained transmission of the disease [2].

Education, level, occupation, housing and the level of income also have a significant contribution to exposure since those with higher education( college/ university) seem to have better occupation hence high level of income and better housing in the community. Apparently, results show majority of the community members have either primary, secondary or no formal education- $90.4 \%$. It is shown that few of these are salaried, many live in either grass thatched or semipermanent houses and low income levels with a higher number of children and fewer number of cattle despite the main economic activity in the area being livestock keeping. This situation increases vulnerability as most people are not economically able to protect themselves from the disease that is reported to hit the poorest among the poor in the communities $[1,3]$. Consistent with this finding, the study by S. P. Singh et al, 2010 [19] reported that low socio-economic status was found to be associated with Visceral leishmaniasis [19]. Another study done in India also showed that higher socio economic status was associated with reduced risk of VL infection compared to lower ones [20]. Similarly, a study done in Kenya and Uganda demonstrated that highest socio economic status was protective to VL infection [21]. A report from systematic review and meta- analysis that assessed subjects' income directly showed that an increase in income was associated with a decrease in the occurrence of the disease [4]. The probable justification for this could be that low income can affect over all status of household and individuals in many aspects. Low income can be associated with poor housing conditions, poor environmental hygienic conditions, poor nutritional status and increased risk of infections $[1,2]$. The housing condition like type of floor, wall,roofing were associated with increase in kala-azar infection, according to this study. This finding is consistent with findings from other studies which indicated that housing condition is one of the most important factors for VL. A case control study done in India demonstrated that thatched wall of housing condition is high risk for the disease [19]. Similar study from India also showed that house made of mud wall was statistically significantly associated with VL infection [22]. The possible reason for this could be due to the fact that thatched and mud walls are most likely to be cracked and favorable for entrance and breeding of the sand fly, the kalaazar vector.

The results also showed that sleeping time for the members of the community at night ranges from 8 p.m. to beyond 11.30 p.m, with majority $-44 \%$ sleeping between 9.30 p.m-10.30 p.m, $22.9 \%$ between 8 p.m-9 p.m, $21.1 \%$ between 10.30 p.m-11.30 p.m with only $12 \%$ sleeping beyond 11.30 p.m.The biting times of sand flies lie between 6.30 p.m-6.30 a.m. at dawn according to the study at Uganda, Sudan and Bangladesh [23, 24]. Clearly, most people especially are perpetually exposed and prone to frequent infections $[25,26]$.

Peoples relationship with dogs according to the results do not predispose the community people to the disease and this is confirmed by WHO, 2005 and MSF, 2006 report on the study at Uganda and along the Kenyan border that the type of Kala-azar found in the area is anthroponotic where the transmission is directly from human to human and not zoonotic that is supposed to be from animals to man; hence dogs are not reservoir hosts of Kala-azar in Loima, except rodents such as rats, squirrels that are seen and even indicated by the medical records, key informant interviews and focus group discussions [27, 28]. A study on factors associated with kala-azar infection in North Gondar zone, Amhara region, North West Ethiopia and a similar study in Addis Zemen, Ethiopia had their results to the contrary that dog ownership was associated with Visceral leishmaniasis and that the finding of epidemiological survey and metaanalysis in the combined data also demonstrated pattern of increasing likelihood of infection for subjects with dogs in the household; with the possible justification being that dogs are reservoir hosts for canine VL and they attract sand flies for search of blood meal [2, 29].

According to this study, majority of the respondents $(80.2 \%)$ revealed that the behaviour or practice of resting, playing or sitting near the termite mounts, predisposes the community to the disease a great deal, as well as also sleeping near the animal homesteads and close to goatherds as alluded by $19.8 \%$ of the respondents.

Majority of the respondents (72.8\%) stated that the cultural festivities, particularly dancing at night (Edong, a) and overgrazing predispose the community to Kala-azar. The rest $(27.2 \%)$ also mentioned that marriage ceremonies due while polygamy, drinking animal blood during the dry season as exposure factors. A high proportion-239 (70\%) of the respondents were exposed to Kala-azar as compared to 102 $(30 \%)$ not. There was an association between the cultural practices and being predisposed to Kala-azar $\left(x^{2}=63.236\right.$, $\mathrm{df}=6, \mathrm{p}=0.002$ ). This is supported by focus group discussions, key informat interviews and other studies $[1,3]$.

The study showed that the human activity of livestock keeping as mentioned by (55\%) of the respondents, is an exposure to kala-azar in the area with deforestation, peasant farming, gold extraction and military service and hunting activities. encourages the presence of the disease

The results further showed that preference for alternative treatments influences the health seeking behavior in the community and thus more exposure to the disease. The study revealed that few of the community members seek treatment from the health facilities as mentioned by $41.1 \%$ of the respondents while majority-58.9\% resort to traditional healers, apply cow-dung or do incision to the affected area. A study on awareness about kala-azar disease and related preventive attitudes and practices in India showed that government hospitals and health centres were the first choice of treatment by $73.6 \%$ of respondents if a suspected case of 
kala-azar occurred in the household [30]. The study showed that majority of the respondents $(80.4 \%)$ have the distance from their houses to animal shed is between 1-200 meters while a small proportion (19.6\%) having theirs between 201500 meters. This is an exposure to the bites of sand fly due to proximity to the animals.

The results have indicated that the disease is endemic in the area, is among the top priority diseases and the most deadly disease after malaria even according to medical records and the key informant interviews [1]. More than 77\% of the respondents have mentioned that kala-azar is a common disease in the area, another $82 \%$ stated that at least a member of their family has once suffered from the disease with a good percentage of $44.3 \%$ also agreeing that they have themselves had an episode of kala-azar.; and this is in consistency of other studies [30, 31]. The results revealed that among the prevalent diseases in the area, Kala-azar is the $2^{\text {nd }}$ parasitic disease $(17.6 \%)$ after malaria $(39.6 \%)$. Kala-azar according to the medical records and key informant interview, is the most neglected tropical disease in the area followed by trachoma. A similar study in India showed that $98 \%$ of the respondents were aware that kala-azar is an endemic, $2^{\text {nd }}$ parasitic after malaria and the most neglected tropical disease in the area $[30,32]$.

A high proportion of $82 \%$ ) of the respondents indicated that a family member had once suffered Kala-azar., with only $18 \%$ reported that this had not happened. It is supported by medical records and other studies, indicating that the disease is prevalent in the area, hence the need for health education and medical intervention for control strategies [30, 33]. Despite that more than a half of the respondents $(55.7 \%)$ mentioned that they have never suffered kala-azar, a good number $(44.3 \%)$ also said that they have once suffered from the disease thus indicating endemicity and prevalence of this disease kala-azar in the area as supported by other studies [2, 4]. A considerable proportion of respondents $205(60 \%)$ correctly mentioned that presence of anti-hills in large numbers makes the disease to spread due to the human encroachment of the vector habitat. Other factors mentioned also by $40 \%$ of the repondents that encourage spread included livestock or cattle keeping, lack of medical facilities or medical intervention and drought and the study is consistent with other studies [2, 31]. Majority of the respondents $(54.8 \%)$ mentioned that they can be able to identify kala-azar in a photo or picture because of the way it is common while $(45.2 \%)$ said either no or they do not know how to identify the disease in a photo or picture. This indicated lack of proper awareness on the disease, is in itself a risk factor $[4,30]$.

Majority of the respondents (88\%) mentioned that HIV/AIDS and it's opportunistic infection like TB do support the spread of kala-azar. Another small number (7\%) mentioned malaria only to be encouraging the spread of the disease while $(5 \%)$ mentioned that all the above encourage spread of this dreadful disease. The results are supported by key informant interviews, focus group discussions and medical records that indicate kala-azar is now becoming an
AIDS defining disease [2, 4].

\section{Conclusions}

Kala-azar is endemic in Loima sub-county of Turkana County, Kenya, for it is among the top priority diseases in the area and it is second parasitic disease in prevalence (17.6\%) in the area after malaria hence a public health problem that needs Integrated Disease Surveillance Response (IDSR). This concurs with MSF 2010; WHO 2014 reports. Social demographic and socio-economic factors that have significance and seem to expose people in the area to kalaazar include; age, where the age groups between 5-29 years are mostly at risk due to their daily activities or occupation; gender, where males who at most sleep outside their houses at night, the biting times for the sand fly. Education level, occupation, housing and the level of income are also a factor since those with higher education( college/ university) seem to have better occupation hence high level of income and better housing in the community. Apparently, results show majority of the community members have either primary, secondary or no formal education. The termite hills associated with Visceral leishmaniasis transmission in Kenya that are common throughout or all over the area, need control strategies such as insecticidal applications to resting habitats such as termite mounds and insecticide barrier spraying and not termite mounds destruction as suggested by some people in the community; since this is a difficult measure for the reason that anthills harbour termites that comprise the locals diet. The feeding propensity of Phlebotomus martini on livestock and the efficacy of zoo- prophylaxis could be enhanced by using the livestock not only to divert the vector from humans to animals but to attract them to contact with insecticide-treated livestock.

\section{References}

[1] WHO(2014). Neglected Tropical Diseases Kenya. Retrieved february 2014,from http://ntdkenya.or.ke.

[2] Kindie Bantie, Fasil Tessema, Desalegn Massa, Yilka Tafere (2014). Factors associated with visceral leishmaniasis infection in North Gondar zone, Amhara region, North West Ethiopia, case control study.

[3] Davies CR, Kager P, Croft SL Sundars (2003). V. leishmaniasis: New approaches to disease control. $\mathrm{Br}$. Med J.326: $377-82$.

[4] Belo VS, Werneck GL, Barbosa DS, Simo es TC, Nascimento BWL, et al. Factors Associated with Visceral Leishmaniasis in the Americas: A Systematic Review and Meta-Analysis. PLoS Negl Trop Dis. 2013;7 (4): e2182. doi:10.1371/journal. pntd.0002182).

[5] Médecins Sans Frontières. Campaign for access to essential medicines. Leishmaniasis Fact sheet. April 2004.

[6] World health organization. Control of the leishmaniases. WHO, Geneva, March 2010; WHO Technical Report Series 949. 
[7] Hassan, M. M.,Elraba a, F. M., Ward, R. D., Maingoni, R. D. \& Elnaiem. D. A. (2004). Detection of high rates of in-village infection transmission of Leishmania donovani in Eastern Sudan. Acta Trop. 92: 77-82.

[8] MSF(2010). Leishmaniasis: Find on line http://www.accessmed-msf.org/campaign/ishoi.shtm.

[9] Alvar J. Canavate. C Molina. R. Moreno. J \& Nieto J (2010). Canine leishmaniasis. Afr parasitol. 57: 1-88.

[10] Boelaert. M. (2000). Visceral leishmaniasis contract a public health perspective Trans. R. Sac Trop. Med hyg 95: 465-471.

[11] Khalil. E. A Zijlistra, E. E Kager P. A. \& El Hassan, A. M (2002). Epidemiology and clinical manifestations of Leishmania donovani infection in two villages in an endemic area in eastern Sudan. Trop Med. Int Health 7: 35-44.

[12] Central Bureau of Stastistics (2009).

[13] Bartlett, J., Kotrlik, J., Williams, H. \& Higgins, C (2002). An analysis of factors associated with research productivity of business education faculty. NABTE Review, 29, 26-32.

[14] Taylor S; (1st ed), (2010) Business statistics. A complete one semester course. Chipperharm Withshire.p51 and 291.

[15] Collin. S. M. Coleman. P. G. Ritmega. K, \& Davidson. R. N. (2006). Unseen Kala-azar deaths in South Sudan (1999-2002). Trop Med int health 11: 509-512.

[16] S. Akter, M. Z. Alam, M. T. Islam1 and M. M. H. Mondal. Seroepidemiological study of visceral leishmaniasis and cattle as a possible reservoir host at Trishal Upazila in Bangladesh. J. Bangladesh Agril. Univ. 2012; 10 (1): 79-86.

[17] Karl Schenkel, Suman Rijal, Siddhartha Koirala, et al. Visceral leishmaniasis in southeastern Nepal: A cross sectional survey on Leishmania donovani infection and its risk factors. Tropical Medicine and International Health. December 2006; 11 (12): 1792-1799.

[18] John Lagu Nyunguraa, Venny C. S Nyambatib, Mugo Muitai and Eric Muchiri. Risk factors for the transmission of kalaazar in Fangak, South Sudan. SSMJ. May; 2011; 4 (2).

[19] S. P. Singh, E. Hasker, A. Picado, K. Gidwani, et al. Risk factors for visceral leishmaniasis in India: further evidence on the role of domestic animals. Tropical Medicine and International Health. July 2010; 15 (2): 29-35.

[20] Epco Hasker, Shri Prakash Singh, Paritosh Malaviya, et al. Visceral Leishmaniasis in Rural Bihar, India. Emerging Infectious Diseases. 2012 October; 18 (10).
[21] Jan H Kolaczinski, Richard Reithinger, Dagemlidet T Worku, et al. Risk factors of visceral leishmaniasis in East Africa: a case-control study in Pokot territory of Kenya and Uganda. International Journal of Epidemiology. 2008;37: 344-352 doi:10.1093/ije/dym275.

[22] Kesari et al. Study of house-level risk factors associated in the transmission of Indian Kala-azar. Parasites \& Vectors. 2010; 3:94.

[23] MSF(2006). Kala-azar information. pg 1-2 available on line, http.www.doctorswithoutborders.org/ news.kalaazar/index.cfm.

[24] Rijal. S. Koirala. S. Van der Stuft. P. \& Boelaert. M (2006). The economic burden of Visceral leishmaniasis for households in Nepal. Trans. R. Soc. Trop. Med Hyg. 100: 838 -841.

[25] Desjeux. P.(2004). Leishmaniasis: current situation and new perspectives. Comp. Immunol. Microbiot. Infect. Dis. 27: 305318.

[26] WHO (2007): Visceral leishmaniasis. Magnitude of the problem.

[27] $\mathrm{MOH}$ (2013). Kala-azar management guidelines. Disease outbreak Management Unit, Division of communicable and vector borne diseases.

[28] Hailu A. Musa AM Royce, Wassuna M ( 2012). Visceral leishmaniasis. New tools are needed.

[29] Seife Bashaye, et al. Risk Factors for Visceral Leishmaniasis in a New Epidemic Site in Amhara Region, Ethiopia. Am. J. Trop. Med. Hyg. 2009; 81 (1): 34-39.

[30] Siddiqui, Narendra Kumar, A Ranjan, K Pandey, VNR Das, RB Verma and P Das (2010) Awareness about kala-azar disease and related preventive attitudes and practices in a highly endemic rural area of India.

[31] Mondal D, Singh SP, Kumar N, et al. Visceral leishmaniasis elimination programme in India, Bangladesh, and Nepal: reshaping the case finding/case management strategy. PLoS Negl Trop Dis 2009; 3: e355. Epub 2009 Jan 13.

[32] Singh. S. P. Reddy. D. C. Rai. M. \& Sundar S (2006). Serious under-reporting of visceral leishmaniasis through passive case reporting in Bihar. India Trop. Med int. Health. 11: 899-905.

[33] World Health Organization. Global plan to combat neglected tropical diseases. 2008-2015; WHO/CDS/NTD/2007.3. 